\title{
Uso de geotecnologias para identificação de diferentes padrões de ocupação urbana da bacia hidrográfica do rio Cará-Cará - Ponta Grossa-PR
}

\author{
Marcos Antonio Miara* \\ Chisato Oka-Fiori ${ }^{* *}$
}

\section{Resumo}

As áreas urbanas apresentam naturalmente uma diversidade quanto aos padrões de uso do espaço fazendo com que cada porção deste possua características específicas. As análises ambientais quando envolvem áreas urbanas podem encontrar dificuldades para identificar e representar tais diferenças. A presente pesquisa propõe um método que se fundamenta em fotointerpretação que avalia determinadas variáveis espaciais, a partir da criação e sobreposição de uma grade retangular a um mosaico aerofotogramétrico que serve como instrumento para a representação da análise. Para cada ponto da grade são definidos valores a partir das variáveis consideradas, os quais são posteriormente interpolados resultando em uma divisão de cinco classes que representam diferentes padrões de ocupação urbana. O método mostrou-se eficiente pois identificou padrões diferenciados de ocupação urbana, além de se mostrar pouco dispendioso e de fácil execução.

Palavras-chave: Análise espacial; Padrões diferenciados de ocupação urbana; Método de identificação.

Mestre em Geografia pela Universidade Federal do Paraná (marmiara@yahoo.com.br).

** Professora Doutora do Departamento de Geografia da Universidade Federal do Paraná. Centro Politécnico (chisato@ufpr.br).

Geosul, Florianópolis, v. 24, n. 47, p 49-68, jan./jun. 2009 
MIARA, M.A. \& OKA-FIORI, C. Uso de geotecnologias para identificação ...

Use of geotechnologies for the identification of different standards

of urban ocupation in the hydrographic bay of Cara-Cara river -

Ponta Grossa-PR

\begin{abstract}
Urban areas are very diverse in relation to the standard practices of space use, what produces specific characteristics in each portion of space. The environmental analyses when involve urban areas may have difficulties to identify and represent these differences. This present work devises a method, based on photointerpretation, which evaluates determined spatial variables, taking as its starting point the creation and superposition of a rectangular grid over an aerophotogrametric mosaic, which serves as an instrument for the representation of the analysis. For each point of the grid, values are defined from the considered variables, which are lately interpolated, resulting into a division of five classes, which represent different standard practices of urban occupation. The method proved to be efficient because it achieved its objectives and, moreover, it showed to be less expensive and of easy execution.
\end{abstract}

Key words: Spatial analysis; Differentiated standards of urban occupation; Method of identification.

\title{
Introdução
}

Os processos de urbanização ocorrem de modos e intensidades diferenciados em cada município. Isto se dá por diversas condicionantes e o resultado deste processo dinâmico é um mosaico composto por variadas situações espaciais, sendo de fácil identificação a existência de locais que apresentem características distintas entre si em um mesmo município, com melhores ou piores condições de ocupação do espaço urbano conforme determinados aspectos que se considere.

Isto se mostra, por exemplo, pelo adensamento urbano, pelas condições das estruturas viárias, sistemas de drenagem, pela 
MIARA, M.A. \& OKA-FIORI, C. Uso de geotecnologias para identificação ...

ocupação de locais impróprios, pela existência ou não de áreas verdes ou permeabilizadas, de áreas de lazer, entre outros fatores.

Diversas pesquisas destinam-se a análises urbanas, e diferentes métodos de análise espacial podem ser empregados, do mesmo modo que diferentes tipos de dados podem ser utilizados. Nas análises geográficas especificamente, há uma perspectiva de se trabalhar com diferentes informações para representação do espaço. A união de aspectos tanto humanos quanto físicos torna-se cada vez mais presente nos estudos pertinentes a esta área de pesquisa, distanciando-os progressivamente da dicotomia ainda presente nesta ciência.

Este trabalho propõe um método destinado à identificação e mapeamento de diferentes padrões de ocupação urbana a partir da utilização de levantamento aerofotogramétrico e sua interpretação com o uso de um Sistema de Informações Geográficas. Como área de estudo foi utilizada a bacia hidrográfica do rio Cará-Cará BHCC, localizada no município de Ponta Grossa, PR.

\section{Fundamentação teórica}

\section{Fragilidade dos ambientes}

Os sistemas ambientais, para Almeida e Tertuliano (1999), sempre estão funcionando perante flutuações no fornecimento de matéria e energia e, cada evento (ação) fornece determinada quantidade de matéria e energia ao sistema, sendo que o valor dessa quantidade representa sua magnitude.

Entretanto, os eventos apresentam variabilidade muito grande no fornecimento dessas quantidades. Os autores dizem que todo fluxo no sistema promove algum efeito, sendo que essas mudanças variam com a intensidade da entrada. Em seu processo de ajustagem, o sistema é capaz de absorver determinada variação sem que ocorram alterações, mas os eventos de alta magnitude muitas vezes provocam ultrapassagem nos limiares de absorção do sistema, promovendo assim, alterações no mesmo, o que salienta as fragilidades do sistema. Para Ross (1995), as fragilidades dos 
MIARA, M.A. \& OKA-FIORI, C. Uso de geotecnologias para identificação ...

ambientes naturais podem ser estabelecidas adotando-se o conceito de Unidades Ecodinâmicas preconizadas por Tricart (1977) e adaptadas por Ross $(1990 ; 1994)$. Segundo Ross (1990), as contribuições de Tricart se completam quando este propõe que a paisagem deve ser analisada pelo seu comportamento dinâmico, partindo da identificação das unidades de paisagem que denomina de unidades ecodinâmicas. Conceber os ambientes dentro desta perspectiva de dinamismo e inter-relações entre seus elementos constituintes possibilita um entendimento a respeito destes, de modo a inferir níveis de fragilidade do ambiente.

Ainda é importante que se considerem as ações humanas sobre o espaço, avaliando as diferentes formas de uso e suas potencialidades de alteração do meio. Segundo Ross (1994) a fragilidade dos ambientes naturais diante das intervenções humanas é maior ou menor em função de suas características genéticas.

Dos resultados negativos do impacto da ocupação antrópica inadequada sobre o meio, são representantes os processos de erosão acelerada dos solos, a perda da reserva de seus nutrientes, a contaminação físico-química dos recursos hídricos e possíveis modificações estruturais dos sistemas hidrográficos, como por exemplo, o assoreamento de várzeas, de reservatórios e canais fluviais (VALÉRIO, 1995).

Para Carvalho (2001), as questões ambientais possuem uma relação direta com o contexto social e afirma que:

“(...) a relação perversa entre a sociedade e a natureza é, antes de tudo, uma relação perversa entre os homens. Resolver e prevenir problemas ambientais tem como prérequisito novas relações com a natureza o que pressupõe, em última análise, novas relações sociais" (CARVALHO, 2001:32).

A urbanização neste contexto representa, acima de tudo, uma forma de relações existentes entre as pessoas e destas com o espaço. Gonçalves e Pereira (2001) interpretam o espaço como tendo um sentido de finalidade, que é o da produção da vida 
MIARA, M.A. \& OKA-FIORI, C. Uso de geotecnologias para identificação ...

humana, e para eles o meio ambiente urbano deve ser considerado resultado da história do homem em seu processo de forma, provocando mudanças, suportando, ou mesmo causando danos ao ambiente.

Antonio Filho (2003) cita diversos fatores, tanto exógenos quanto endógenos, que podem gerar condições favoráveis para o crescimento de um núcleo urbano, o que faz entender a necessidade de planejamento intensivo para tal processo. Hasenack e Weber (2000) comentam que o planejamento urbano no Brasil tem sido feito levando-se em consideração inúmeros critérios e objetivos, mas geralmente deixa a desejar em relação a aspectos técnicos, ambientais e de legislação.

Ross (1994) complementa que a partir de uma perspectiva de planejamento econômico e ambiental do território, quer seja ele a nível municipal, estadual, federal, bacia hidrográfica, ou qualquer outra unidade espacial, é necessário que as intervenções humanas sejam planejadas com objetivos claros de ordenamento territorial, tomando-se como premissas a potencialidade dos recursos naturais e humanos e as fragilidades dos ambientes.

Desta forma, cabe salientar a importância do planejamento do crescimento das cidades, e estudar as tendências através do monitoramento da expansão da mancha urbana e a sua interação com o meio físico (VALÉRIO, et al 2003).

Referindo-se ao risco da expansão urbana como fator de comprometimento aos recursos hídricos, Andreoli (2003) comenta que o grande crescimento acompanhado pela ocupação inapropriada dos mananciais contribui para alteração do regime hídrico e redução da qualidade das águas, e que planos de uso e ocupação do solo inadequados ou inexistentes permitem o avanço desordenado, sem que haja critérios e estrutura de saneamento básico sobre as bacias de captação de água para consumo humano, animal e / ou industrial.

Referindo-se ao problema da erosão urbana, Fendrich et al (1997) afirmam que este está estreitamente ligado ao rápido crescimento da população e urbanização espontânea e, portanto, 
MIARA, M.A. \& OKA-FIORI, C. Uso de geotecnologias para identificação ...

seu controle e prevenção em grande parte dependem do adequado planejamento do desenvolvimento urbano.

Com relação ao processo de urbanização em áreas periféricas, Gonçalves e Pereira (2001) salientam que, na maioria das vezes, este ocorre de maneira irregular e, pela própria iniciativa da população carente, que ocasionalmente ocupa áreas impróprias tais como as de utilidade pública, fundos de vale e outras áreas de preservação permanente, gerando um uso inadequado do solo urbano. Os mesmos autores complementam que as periferias urbanas das cidades médias se caracterizam basicamente por aspectos sócio-ambientais comuns, e que as diferenças presentes no espaço urbano podem ser entendidas como resultado do processo de má distribuição de renda, provocando inúmeras desigualdades sociais, sendo que o alto valor das propriedades, aliado a constantes práticas de especulação imobiliária, afasta a população carente das áreas centrais, muitas vezes privando a mesma de serviços básicos, tais como comércio, transporte, educação e segurança.

Traçando considerações sobre a urbanização sustentável, Carvalho (2001) cita que é necessário retomar a necessidade de uma reforma urbana que incorpore a questão do acesso à terra e à cidade, o planejamento urbano, e um zoneamento geo-ambiental.

Com relação às áreas naturais, estas são, para Carvalho (2001), essenciais tanto no meio natural como no meio ambiente construído, e o autor cita que:

"Praças, áreas verdes, e áreas institucionais para equipamentos comunitários são essenciais a uma vida urbana tanto como as várzeas e mananciais são importantes na gestão ambiental do sítio urbano" (CARVALHO, 2001: 31).

Portanto, pode-se considerar que a urbanização é um processo que representa fonte de alteração e conseqüentemente de impactos sobre o ambiente, agindo em variadas escalas sobre os sistemas ambientais conforme as condições em que ocorre, o que torna relevante a aplicação de análises que auxiliem a um processo de urbanização congruente as expectativas sócio-ambientais. 
MIARA, M.A. \& OKA-FIORI, C. Uso de geotecnologias para identificação ...

\section{Análise sistêmica}

A aplicação da abordagem sistêmica aos estudos na geografia serviu para melhor focalizar as pesquisas e para delinear com maior exatidão o setor de estudo desta ciência, além de propiciar oportunidade para reconsiderações críticas de muitos dos seus conceitos (CHRISTOFOLETTI, 1979).

Para Morin (2005) todos os objetos da física, biologia, da sociologia, astronomia, átomos, moléculas, células, organismos, sociedades, astros, galáxias, constituem sistemas, fazendo com que o fenômeno-sistema seja hoje evidente em tudo. Para este autor, o que é preciso compreender sobre o sistema são as características de unidade complexa, pois o sistema é uma unidade global, não elementar, já que é formado por partes diversas e interrelacionadas. Para ele a complexidade do sistema reflete-se no fato de que este, enquanto todo, não poder ser reduzido às partes e nem as partes ao todo, sendo preciso conceber o sistema em conjunto, de modo complementar e antagônico, as noções de partes e de todo.

Tricart (1977) conceitua um sistema como um conjunto de fenômenos que se processam mediante fluxos de matéria e energia, sendo que estes fluxos originam relações de dependência mútua entre os fenômenos. A conseqüência disso é que o sistema apresenta propriedades que lhe são próprias diferindo da soma das propriedades dos seus componentes, e uma destas propriedades é ter dinâmica própria, específica do sistema.

Ross (1995: 73) cita que

“(...) na natureza as trocas de energia e matéria se processam através de relações em equilíbrio dinâmico. Esse equilíbrio, entretanto, é freqüentemente alterado pelas intervenções do homem nas diversas componentes da natureza, gerando estados de desequilíbrios temporários ou até permanentes".

Para Drew (1994), a intensidade das alterações depende primeiramente da tensão aplicada ao sistema pelo homem e, em segundo lugar, do grau de sensibilidade do próprio sistema. 
MIARA, M.A. \& OKA-FIORI, C. Uso de geotecnologias para identificação ...

Tricart (1977) definiu que os ambientes que estão em equilíbrio dinâmico, são estáveis e em desequilíbrio são instáveis. Para ampliar a utilização desses conceitos ao planejamento ambiental, Ross (1990 e 1994) estabeleceu as Unidades Ecodinâmicas Instáveis ou de Instabilidade Emergente e as Unidades Ecodinâmicas Estáveis, que apesar de estarem em equilíbrio dinâmico, apresentam Instabilidade Potencial em vários níveis diante suas características naturais e a sempre provável ou possível inserção antrópica. Deste modo, níveis ou categorias foram definidos variando de Muito Fraca a Muito Forte para ambas modalidades de Unidades Ecodinâmicas (ROSS, 1995).

De uma forma geral, Ross (1995) cita que os ambientes antropizados revelam-se por diferentes níveis de intervenções das sociedades humanas na natureza com sentido de apropriação dos recursos naturais, sendo que este procedimento leva o homem a alterar as características naturais do ambiente e produzir diferenciados cenários na ordenação espacial.

Sobre as áreas urbanizadas, Ross (1994) cita que é preciso distinguir padrões de urbanização quanto a alguns aspectos como níveis de impermeabilização do solo, a ocorrência de áreas verdes, a infra-estrutura como canalização das águas pluviais, asfaltamento, padrões das edificações, entre outros. Miara et al (2005), utilizando informações provenientes de censos demográficos, demonstraram a possibilidade de espacialização e análise de diferentes condições urbanas, delimitadas por setores censitários, considerando diferentes padrões de vida da população, de infra-estrutura entre outras que condicionam também variações presentes na forma com que a urbanização ocorre.

Porém, em análises sobre fragilidade ambiental é comum que ocorra que as áreas urbanizadas sejam consideradas como uma cobertura uniforme, sendo dado a estas áreas somente um peso com relação a sua influência nos processos de degradação ambiental. 
MIARA, M.A. \& OKA-FIORI, C. Uso de geotecnologias para identificação ...

A Bacia Hidrográfica do Rio Cará-Cará - BHCC

A bacia hidrográfica do Rio Cará-Cará localiza-se no município de Ponta Grossa, PR, possui uma área de $102,18 \mathrm{~km}^{2}$, e faz parte da bacia hidrográfica do rio Tibagi sendo afluente da sua margem direita. Localiza-se na parte central do município abrangendo a parte Leste e Sudeste do perímetro urbano da cidade e parte da área rural do município, sendo que cerca de $61,6 \mathrm{~km}^{2}$ de sua área encontram-se dentro dos limites urbanos e o restante, cerca de $40,5 \mathrm{~km}^{2}$, na área rural do município. Localiza-se entre as coordenadas UTM $584.634 \mathrm{~m}$ e $597.960 \mathrm{~m}$ em $X$, e $7.214 .090 \mathrm{~m}$ e 7.225.298 m em $Y$ (MIARA, 2006).

A BHCC possui altitudes que variam de 779 a 1.027 metros sendo que as maiores altitudes encontram-se na parte Leste da bacia e diminuem no sentido Oeste e Sul, para onde correm os principais canais. Suas principais nascentes se encontram em sua parte Leste para o rio Cará-Cará. Também na porção Noroeste onde se encontram as cabeceiras do principal tributário, o arroio Olarias entre as cotas de 900 e 920 metros (MIARA, 2006).

Quanto a variação clinográfica, em sua maior parte a bacia apresenta baixas declividades as quais aumentam sem grandes variações sentido encostas abaixo. Os maiores declives associamse em parte as rupturas do relevo e encontram-se principalmente nas cabeceiras do arroio Olarias onde há a ocorrência de intrusões de diques e soleiras de Diabásio e ao longo de sua margem esquerda, e em algumas áreas isoladas junto a drenagem do rio Cará-Cará e de alguns afluentes de sua margem esquerda onde se formam vales encaixados (MIARA, 2006).

A geologia na área da BHCC é composta na porção Oeste pela Formação Ponta Grossa formada por Folhelhos e Siltitos cinzentos, localmente betuminosos, com intercalações de Arenitos muito finos, esbranquiçados. Apresenta estruturas como laminação paralela, ondulada e flaser (MINEROPAR, 2001). No setor Leste da bacia ocorre Formação Furnas que é constituída por Arenitos médios a grosseiros com estratificações cruzada e horizontal, 
MIARA, M.A. \& OKA-FIORI, C. Uso de geotecnologias para identificação ...

subordinadamente Arenitos conglomeráticos e Siltitos
esbranquiçados (MINEROPAR, 2001).

Há ainda a presença de diques e soleiras de Diabásio constituídos por derrames de rochas ígneas, de idade JurássicaCretácea, principalmente nas cabeceiras do arroio Olarias onde se encontram as maiores declividades da BHCC, e também nas cabeceiras de um afluente do mesmo arroio onde existe a exploração mineral em atividade. Os depósitos Quaternários ocorrem nas cotas mais baixas nas planícies aluviais do rio CaráCará e de acordo com Medeiros e Melo (2001), são constituídos por alternância de camadas decimétricas a submétricas de origem aluvial (argilas e areias).

Na BHCC ocorrem cinco tipos de solos (HIGA, 2003). Os Latossolos ocupam a maior parte da BHCC distribuindo-se por $72,1 \%$ da área. A classe que representa uma associação entre Cambissolo e Podzólico ocupa cerca de $25 \%$ da bacia e distribui-se principalmente nas cabeceiras do arroio Olarias e pelo vale do mesmo rio. Esta classe apresenta as maiores variações de declividade onde cerca de $15 \%$ de sua totalidade de área apresenta declives entre 12 e $20 \%$, e $5 \%$ de sua área com declives de 20 a $30 \%$. Quanto ao substrato geológico, em torno de $74 \%$ desta classe está sobre a Formação Ponta Grossa. Os solos hidromórficos sobrepõem totalmente os depósitos Quaternários e possuem um relevo praticamente plano (MIARA, 2006).

Sobre a dinâmica do uso e ocupação da terra da BHCC, Miara (2006) assinala que entre os anos de 1980 e 2002 houve alternâncias significativas nas modalidades de uso da bacia. Notase num primeiro momento que classes como "Herbáceas", "Campo" e "Capões", as quais subentendem não apresentar usos diretos, representavam em 1980 cerca de $52 \%$ da bacia, enquanto que em 2002 este percentual caiu para cerca de 34\% da área, demonstrando assim a diminuição de áreas que não possuíam usos diretos em cerca de $34 \%$.

Ao mesmo tempo, pôde ser observado que as classes de uso que caracterizam as atividades rurais como "Cultivo Temporário", 
MIARA, M.A. \& OKA-FIORI, C. Uso de geotecnologias para identificação ...

"Cultivo Florestal", "Pínus" e "Pastagem" ocupavam em 1980 cerca de $35 \%$ da área da BHCC, enquanto que em 2002 as mesmas classes representavam cerca de $45 \%$ da BHCC, demonstrando um aumento em cerca de $28 \%$.

Assim, de modo geral, pode-se dizer que houve uma diminuição das áreas com maior grau de proteção do solo em cerca de $34 \%$, e que aumentaram as áreas com características rurais em cerca de $28 \%$. Quanto às áreas urbanas, estas apresentaram um acréscimo de $52 \%$ no mesmo período, o que demonstra que houve uma intensificação de uso da terra da BHCC durante os anos de 1980 e 2002 (MIARA, 2006).

\section{Objetivos}

Esta pesquisa tem por objetivo demonstrar um procedimento metodológico baseado na identificação e delimitação espacial de diferentes padrões de ocupação urbana a partir de determinadas variáveis espaciais.

\section{Procedimentos metodológicos}

Esta pesquisa teve como preceitos metodológicos os princípios sistêmicos para interpretação do ambiente procurando delinear uma proposta para se identificar e espacializar diferentes padrões de ocupação urbana expressos pela extensão e pela continuidade espacial.

Considerou-se que a complexidade dos ambientes, sejam eles naturais ou alterados pelo homem, é de tal ordem que não se podem estabelecer seus limites territoriais com precisão, já que não se têm modificações bruscas de uma condição ambiental para outra, assim como considerado por Ross (1990).

A base para a formação do banco de dados foi construída utilizando o software de geoprocessamento Spring v. 4.3 Beta 4 (INPE, 2005) a partir do qual todos os procedimentos foram realizados, sendo gerada através de foto-interpretação de um mosaico aerofotogramétrico em escala 1:30.000 e de visitas a campo para uma distinção de alguns dos padrões de ocupação. 
MIARA, M.A. \& OKA-FIORI, C. Uso de geotecnologias para identificação ...

Sendo importante o fracionamento do quadro ambiental, podendose identificar quantos quadros que se queira em um determinado território, por menor que este seja, dependendo da escala de trabalho utilizada (ROSS, 1990), foi realizada uma interpolação dos dados gerados para identificar as diferenciações entre os padrões de urbanização.

O primeiro procedimento foi a definição das características de uso urbano consideradas na avaliação. Foram analisadas a Densidade de Ocupação Urbana, a Densidade de Cobertura de Vegetação, e a pavimentação das Vias. Para cada um destes critérios foram definidas três classes com seus respectivos valores, como seguem no Quadro 01.

Quadro 01: Critérios para padrões de ocupação urbana da BHCC em 2002

\begin{tabular}{|c|c|c|c|}
\hline \multicolumn{2}{|c|}{ Densidade da Ocupação Urbana } & \multicolumn{2}{|c|}{ Densidade da Cobertura Vegetal } \\
\hline Classe & Valor & Classe & Valor \\
\hline Baixa & 1 & Baixa & 3 \\
\hline Média & 2 & Média & 2 \\
\hline Alta & 3 & Alta & 1 \\
\hline \multicolumn{4}{|c|}{ Vias } \\
\hline \multicolumn{3}{|c|}{ Classes } & Valor \\
\hline \multicolumn{3}{|c|}{ Vias pavimentadas } & 1 \\
\hline \multicolumn{3}{|c|}{ Vias pavimentadas intercaladas com vias não pavimentadas } & 2 \\
\hline \multicolumn{3}{|c|}{ Vias não pavimentadas } & 3 \\
\hline
\end{tabular}

Para a Densidade de Ocupação Urbana considerou-se que quanto mais baixa, menor seria a pressão oferecida ao ambiente. Para a Cobertura Vegetal a interpretação foi inversa já que, quanto maior for a disponibilidade de ambientes vegetados, mais facilmente pode se (re) estabelecer proximidade aos padrões de equilíbrio. Quanto às Vias, estas foram interpretadas como oferta de infra-estrutura urbana disponível.

O segundo passo foi fazer uma grade retangular com eqüidistância de 400 metros entre cada ponto. Esta grade foi sobreposta ao mosaico aerofotogramétrico a partir do qual se realizou uma avaliação empírica para a definição dos valores de 
MIARA, M.A. \& OKA-FIORI, C. Uso de geotecnologias para identificação ...

cada ponto da grade pelos critérios utilizados na análise (Figura 01). Para cada ponto considerou-se tanto onde este se localizava, assim como suas áreas circunvizinhas, as quais compreendiam os limites estipulados pelo próprio interpolador utilizado na análise.

Após a definição dos valores a partir da soma entre as variáveis em cada ponto, foi realizada a interpolação dos mesmos para gerar uma Grade Retangular que é um modelo digital que aproxima superfícies através de um poliedro de faces retangulares (INPE, 2005). Como método de interpolação foi usado o de 'Média Ponderada' onde o valor de cota de cada ponto da grade é calculado a partir da média ponderada das cotas dos oito pontos vizinhos mais próximos ao ponto avaliado (INPE, 2005).

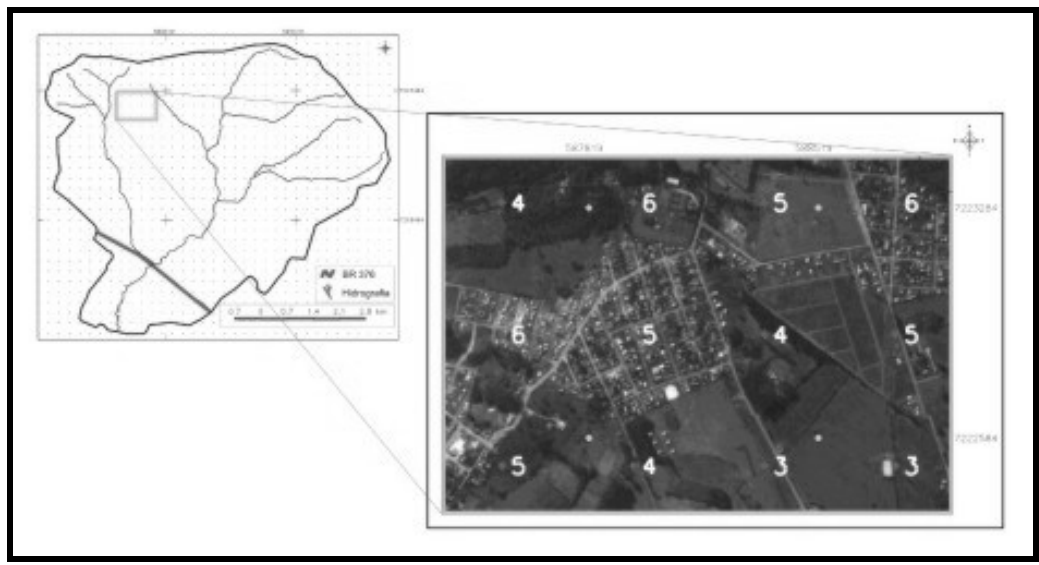

Figura 01: Representação da sobreposição da Grade Retangular sobre o Mosaico Aerofotogramétrico de 2002.

Após a conclusão da interpolação, foi realizado um 'Fatiamento' da Grade Retangular em cinco intervalos que representam diferentes classes de padrões de urbanização no que tange a maior potencialidade de influências à degradação ambiental (Figura 02). Para que fossem excluídas da análise as áreas que não representassem as áreas urbanizadas, foi realizado um cruzamento 
MIARA, M.A. \& OKA-FIORI, C. Uso de geotecnologias para identificação ...

com um mapa das áreas urbanizadas da BHCC no ano de 2002 (Figura 03).

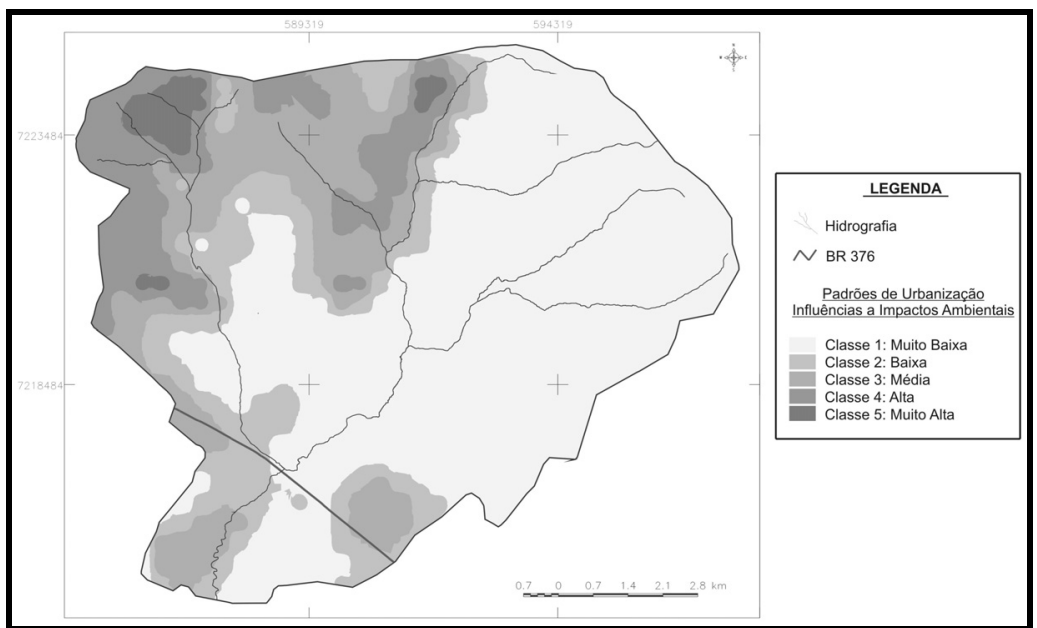

Figura 02: Classes de padrões diferenciados de ocupação urbana da BHCC após interpolação e fatiamento.

O resultado final demonstrado na Figura 04 apresenta para a BHCC seus diferentes padrões de ocupação urbana para o ano de 2002, conforme as variáveis consideradas nesta pesquisa, ou seja, conforme a densidade de ocupação urbana, a presença ou não de cobertura vegetal e a condição das vias. 
MIARA, M.A. \& OKA-FIORI, C. Uso de geotecnologias para identificação ...

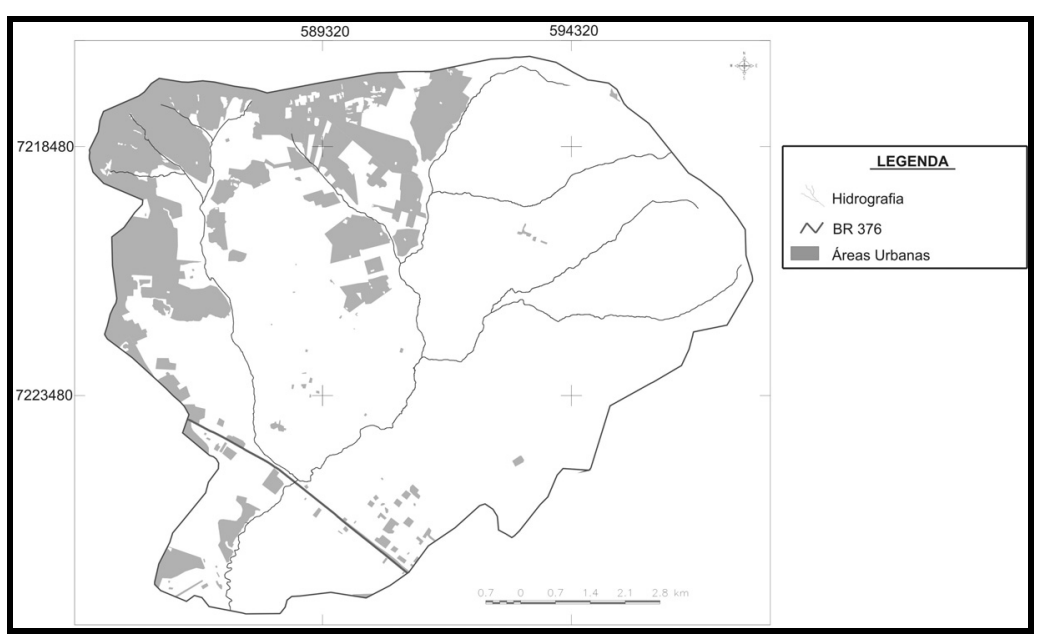

Figura 03: Áreas urbanizadas da BHCC em 2002.

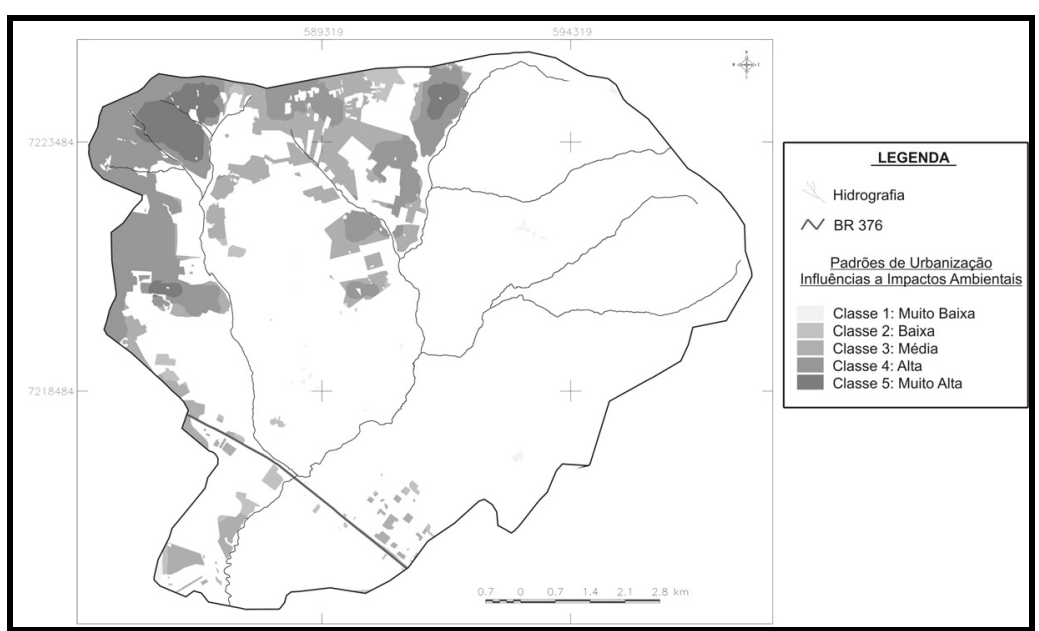

Figura 04: Classes de padrões diferenciados de ocupação urbana da BHCC. 
MIARA, M.A. \& OKA-FIORI, C. Uso de geotecnologias para identificação ...

\section{Considerações finais}

A metodologia aqui proposta atingiu seu propósito, o qual era o de possibilitar uma diferenciação de padrões de ocupação urbana conforme determinadas condicionantes a partir da interpretação aerofotogramétrica.

Algumas vantagens foram observadas para o método, dentre as quais pode ser ressaltada a rapidez em obtenção de informação do mesmo modo que o método pode ser considerado simples já que utiliza procedimentos de amplo conhecimento na área das geotecnologias. Outro ponto positivo é sua versatilidade, pois permite que diferentes modelagens sejam realizadas conforme os objetivos a que cada pesquisa se propõe. Isso se demonstra pelas possibilidades de alteração na eqüidistância dos pontos da grade adequando-a a escala mais apropriada de trabalho, assim como a possível alteração das variáveis a serem utilizadas e no grau de detalhamento que pode ser dado aos níveis a serem definidos. O baixo custo é outro ponto positivo que deve ser considerado, pois possibilita mais facilmente a difusão do método.

O maior ganho porém, se encontra na possibilidade de gerar uma informação que pode ser cruzada com uma variedade de outras informações conforme propósitos específicos, como os mapas de fragilidades ambientais e considerar a partir de então, as influências variadas das atividades antrópicas sobre o meio de acordo com as intensidades e modalidades com que estas são implantadas. Do mesmo modo, podem ser cruzadas com informações quantitativas de padrões de ocupação urbana ou de infra-estrutura enriquecendo assim uma análise desta ordem. Serve também para análises mais diretas com relação a informação gerada, ou seja, para a identificação por exemplo de locais que precisam de uma maior atenção e / ou intervenção por parte do poder público conforme as variáveis avaliadas.

Há que se considerar, entretanto, que o método apresenta também suas limitações. A primeira estaria no fato de que ele apresenta uma carga de subjetividade em sua análise a qual depende das perspectivas do pesquisador. $\mathrm{O}$ fato de ser uma análise 
MIARA, M.A. \& OKA-FIORI, C. Uso de geotecnologias para identificação ...

empírica reafirma esta sua característica, devendo, portanto ser considerada tal condição e limitação. Isso faz com que seja importante que o pesquisador tenha consciência de seus critérios e de suas formas de leitura espacial a partir do levantamento aerofotogramétrico, da mesma forma que é fundamental que se procure manter uma padronização para a análise da área estudada como um todo. Os autores complementam que o fato destes terem conhecimento sobre a área estudada, tendo percorrido esta quase que em sua plenitude, facilitou em muito na análise e na definição de seus padrões criteriais.

Outro ponto a considerar é a questão da defasagem temporal existente nos levantamentos aerofotogramétricos que em certas regiões atingem níveis que poderão comprometer a qualidade do resultado final da pesquisa.

De uma forma geral, os autores consideram que o método se mostrou eficaz, de fácil execução e que não demanda de muito tempo para ser concluído. Que apresenta versatilidade quanto sua aplicabilidade e que contribui para as análises ambientais já que passa a considerar a urbanização como uma forma de uso do espaço que possui variadas condições com relação aos impactos que pode causar de acordo com as formas e intensidades com que esta acontece.

\section{Referências bibliográficas}

ALMEIDA, Josimar Ribeiro de; TERTULIANO, Marcos Faria. Diagnose dos sistemas ambientais: métodos e indicadores. In: CUNHA, Sandra Baptista da; GUERRA, Antonio José Teixeira (Orgs). Avaliação e perícia ambiental. Rio de Janeiro: Bertrand Brasil, 1999. p. 115-170. 284p.

ANDREOLI, Cleverson V., et al. A crise da água e os mananciais de abastecimento - $A$ disponibilidade de água na região metropolitana de Curitiba. in ANDREOLI, Cleverson V. (editor) Mananciais de abastecimento: planejamento e gestão. 
MIARA, M.A. \& OKA-FIORI, C. Uso de geotecnologias para identificação ...

Estudo de caso do Altíssimo Iguaçu. Curitiba: Sanepar Finep, 2003. v1 494p.

ANTONIO FILHO, Fadel David. Crescimento urbano e recursos hídricos: o caso de Rio Claro (SP) - Estudos Geográficos, Rio Claro, 1(1): 55-62, junho 2003.

CARVALHO, Pompeu Figueiredo de. Problemas ambientais na produção da cidade e da habitação de interesse social. In CARVAlHO, P. F. de \& BRAGA, R. (Org.) - Perspectivas de gestão ambiental em cidades médias. Rio Claro: UNESP-IGCE, Laboratório de Planejamento Municipal, Deplan, 2001. 138p.

CHRISTOFOLETTI, A. Análise de Sistemas em Geografia: introdução. São Paulo: HUCITEC - EDUSP, 1979. 106p.

DREW, David. Processos Interativos Homem-Meio Ambiente. Trad. João Alves dos Santos. Rev. Suely Bastos. Coord. Editorial: Antonio Christofoletti. 3 ed. Rio de Janeiro: Bertrand Brasil, 1994. 206p.

FENDRICH, Roberto; OBLADEN, Nicolau Leopoldo; AISSE, Miguel Mansur; GARCIAS Carlos Mello. Drenagem e Controle da Erosão Urbana. 4. ed. Curitiba: Champagnat, 1997. 485p.

GONÇALVES, A. R. \& PEREIRA, M. F. V. Aspectos ambientais em áreas periféricas urbanas. In CARVALHO, P. F. \& BRAGA, R. (org.) Perspectivas de gestão ambiental em cidades médias. Rio Claro: Deplan/UNESP, 2001. p 129-132. 138p.

HASENACK, H.; WEBER, E. Derivação de novas informações cadastrais para o planejamento urbano através de Sistemas de Informação Geográfica. UFRGS - Centro de Ecologia, Centro de Recursos Idrisi, $2000 . \quad$ Consultado em http://delmonio.ecologia.ufrgs.br/idrisi/artigos/sigurb3.pdf em 08/12/2001.

HIGA, A. R. (Coord.). SIFLOR. Curitiba, 2003. 1 CD-ROM. 
MIARA, M.A. \& OKA-FIORI, C. Uso de geotecnologias para identificação ...

INPE - Instituto Nacional de Pesquisas Espaciais, Spring v. 4.1.1, 2005.

MEDEIROS, Carla Valéria; MELO, Mário Sérgio. Processos erosivos no espaço urbano de Ponta Grossa. in Carmencita de $\mathrm{H}$. M. Ditzel e Cicilian L. L. Sahr (org.) Espaço e cultura - Ponta Grossa e os Campos Gerais. Editora UEPG, Ponta Grossa, 2001. v1 520p.

MIARA, Marcos Antonio. Análises têmporo-espaciais da fragilidade ambiental da bacia hidrográfica do rio Cará-Cará, Ponta Grossa - PR. Dissertação de Mestrado. Curso de PósGraduação em Geografia, UFPR, Curitiba, 2006. 182 p. Disponível em http://dspace.c3sl.ufpr.br/dspace/simple-search?query=miara.

MIARA, M. A.; SANTOS, L. K. S.; OKA - FIORI, C. Identificação de áreas potencialmente poluídas da bacia hidrográfica do arroio Lajeado Grande, Ponta Grossa - PR, através de dados censitários com o uso de SIG. In XI Simpósio Brasileiro de Geografia Física Aplicada, 2005, São Paulo. Anais. P 152. $254 \mathrm{p}$.

MINEROPAR. Atlas Geológico do Estado do Paraná. Curitiba, 2001. 125p.

MORIN, Edgar. O método 1: a natureza da natureza. Trad. Ilana Heineberg. Porto Alegre: Ed. Sulina, $2^{\mathrm{a}}$ ed., 2005. 479p.

ROSS, Jurandyr L. Sanches. Geomorfologia Ambiente e Planejamento. São Paulo: Contexto, 1990. 85p.

Análise Empírica da Fragilidade dos Ambientes Naturais e Antropizados. Revista do Departamento de Geografia n.8, USP - Faculdade de Filosofia, Letras e Ciências Humanas, 1994. p 77-106.

Análises e Sínteses na Abordagem Geográfica da Pesquisa para o Planejamento Ambiental. Revista do Departamento de Geografia n. 9, USP - Faculdade de Filosofia, Letras e Ciências Humanas, 1995. p 65-76. 
MIARA, M.A. \& OKA-FIORI, C. Uso de geotecnologias para identificação ...

TRICART, Jean. Ecodinâmica. Rio de Janeiro, IBGE, Diretoria Técnica, SUPREN, 1977.97p.

VALÉRIO, M. F. Gerenciamento de Bacias Hidrográficas com aplicação de técnicas de geoprocessamento. in: Sâmia Maria Tauk-Tornisielo (Org), et al. Análise Ambiental: estratégias e ações. São Paulo: T.A. Queiroz/ Fundação Salim Farah Maluf; Rio Claro, SP: Centro de Estudos Ambientais - UNESP, 1995. 381p.

VALÉRIO, M. F.; SERAFIM, C. R.; DIAS, L. A. V. Análise Temporal da Expansão Urbana em Área de Risco à Erosão com o Auxílio de Técnicas de Sensoriamento Remoto e Geoprocessamento. IP\&D - Instituto de Pesquisa e Desenvolvimento - UNIVAP consultado em http://www.cartografia.org.br/xixcbccd/artigos/c5/CV-

07/SBC99a.pdf, em 01/06/2003. 